\title{
PENGARUH TEKANAN ANISOTROPIK PADA BINTANG NEUTRON
}

\author{
A. M. Setiawan ${ }^{1, a)}$, A. Sulaksono ${ }^{2, b)}$ \\ ${ }^{1,2}$ Departemen Fisika FMIPA UI, Kampus UI Depok, 16424

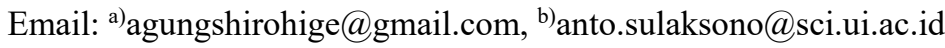

\begin{abstract}
Abstrak
Kami menyelidiki faktor anisotropik $\sigma$ dari bintang neutron berdasarkan beberapa model. Model yang digunakan dalam penyelidikan kami adalah model dari Doneva-Yazadjiev (DY), Herrera-Barreto (HB), dan Bowers-Liang (BL). Pada inti bintang neutron diasumsikan tersusun dari nukleon, lepton dan hyperon. Untuk ketiga model anisotropik tersebut, prediksi massa maksimumnya konsisten dengan observasi massa dari PSR J1614-2230 dan PSR J0348+0432.
\end{abstract}

Kata Kunci: Hyperon, Bintang Neutron, dan Tekanan Anisotropik

\begin{abstract}
We investigate the anisotropic factor $\sigma$ of neutron stars based on the Doneva-Yazadjiev (DY), Herrera-Barreto (HB), and Bowers-Liang (BL) anisotropic models. We assume that the neutron stars matter consist of nucleons, leptons, and hyperons. We obtain that the corresponding models predict neutron stars maximum mass consistent with PSR J1614-2230 and PSR J0348+0432.
\end{abstract}

Keywords: Hyperon, Neutron Stars, and Anisotropic Pressure.

\section{Pendahuluan}

Penetapan massa maksimum bintang neutron pada saat ini berasal dari 2 pengukuran. Pertama, massa $1.97 \pm 0.04 M_{\odot}$ dari pulsar J1614-2230 yang diukur Shapiro delay [1]. Dan yang kedua, massa $2.01 \pm 0.04 M_{\odot}$ dari pulsar $\mathrm{J} 0348+0432$ yang diukur dari gravitational redshif (Z) [2]. Sedangkan dari analisis yang diperoleh saat ini mengenai distribusi massa dari jumlah pulsar dengan pengukuran massa yang presisi, massa gravitasi $M_{G} \sim 2.1 M_{\odot}$ dapat dianggap sebagai sebuah massa maksimum $\left(M_{\max }\right)$ bintang neutron [3].

Untuk mencapai massa maksimum bintang neutron yang lebih rendah dari $2,1 M_{\odot}$ [3] dapat dipenuhi dengan banyak model, jika inti bintang neutron hanya mengandung nucleon dan lepton. Namun, adanya nucleon dan lepton saja dalam inti bintang neutron ini secara fisis tidaklah realistis [4].

Secara umum, banyak model nuklir yang cocok dengan data eksperimen hyper-nuclei yang memprediksi keberadaan hyperon pada materi dengan kerapatan yang melebihi 2-3 kali kerapatan saturasi nuklir $\left(\rho_{0}=0.16 \mathrm{fm}^{-3}\right)$ [5]. Selain itu, keberadaan partikel seperti hyperon pada inti bintang neutron mempunyai dampak yang penting pada pendinginan bintang neutron [6]. Akan tetapi, prediksi massa maksimum bintang neutron dengan hyperon di intinya selalu lebih kecil daripada bintang neutron tanpa hyperon [6,7]. Sehingga kita dapat berargumentasi [8] bahwa tekanan pada materi bintang neutron bersifat anisotropik. Hal ini merupakan pengembangan asumsi awal yang dipahami para peneliti menyatakan bahwa tekanan dalam bintang neutron adalah isotropik.

Tekanan anisotropik dapat disebabkan oleh adanya medan magnetik dan medan listrik yang kuat, kondensasi boson, perbedaan jenis fase transisi, keberadaan inti padat atau super fluidity [4]. Penelitian yang terbaru terhadap sifat bintang neutron anisotropik dapat ditemukan pada referensi [8-10] dan dikuatkan oleh hasil penelitian lainnya yang terdapat pada referensi [11-14].

Dalam penelitian ini, diasumsikan bahwa tekateki keberadaan hyperon di bintang neutron dapat dipecahkan dengan mempertimbangkan tekanan dalam materi bintang neutron bersifat anisotropik [5-7,15-18]. Properti bintang neutron sendiri dihasilkan melalui Equation of state (EOS) materi bintang yang dimasukkan ke dalam persamaan Tolmann-Oppenheimer-Volkoff (TOV), yang dimodifikasi ke dalam tiga model anisotropik, yaitu model dari Doneva-Yazadjiev (DY), HerreraBarreto (HB) dan Bowers-Liang (BL). Hasil yang diharkapkan dalam penelitian ini yaitu massa maksimum bintang neutron anisotropik, konsisten dengan observasi massa dari PSR J1614-2230 dan PSR J0348+0432. 


\section{Metode Penelitian}

Metode yang digunakan dalam penelitian ini adalah metode analitik dan metode numerik. Equation of state (EOS) materi bintang neutron dibuat berdasarkan model medan rerata relativistik yang diperluas (Extended version Relativistic Mean Field atau ERMF) [4] dengan memasukkan partikel hyperon $(H=\Lambda, \Sigma$, dan $\Xi)$ di inti dalam bintang neutron. Sedangkan untuk inti luar diasumsikan tersusun atas baryon dan lepton [4]. Dalam model ERMF, baryon berinteraksi melalui pertukaran medan meson $(M)$, yaitu $\sigma, \omega, \rho$ dan $\phi$. Baryon berisi nucleon yang terdiri dari proton dan neutron $(N=p$ dan $n)$, sedangkan lepton terdiri dari elektron dan muon $(l=e$ dan $\mu)$ [4]. Maka untuk menghitung EOS, kerapatan lagrangian total dari semua partikel tersebut dapat ditulis sebagai berikut [16]:

$$
\mathcal{L}=\mathcal{L}_{B}^{\text {free }}+\mathcal{L}_{M}^{\text {free }}+\mathcal{L}_{B M}^{\operatorname{lin}}+\mathcal{L}^{\text {nonlin }}+\mathcal{L}_{l}^{\text {free }}
$$

Besar kerapatan Lagrangian baryon bebasnya yaitu [4]:

$$
\mathcal{L}_{B}^{\text {free }}=\sum_{B=N, \Lambda, \Sigma, \Xi} \bar{\psi}_{B}\left[i \gamma^{\mu} \partial_{\mu}-M_{B}\right] \psi_{B}
$$

dimana $\psi_{B}$ adalah medan baryon dan jumlahnya diperoleh dari $N, \Lambda, \Sigma$, dan $\Xi$ baryon. Selanjutnya, kerapatan Lagrangian untuk meson bebas yaitu [4]:

$$
\begin{aligned}
\mathcal{L}_{M}^{\text {free }}= & \frac{1}{2}\left(\partial_{\mu} \sigma \partial^{\mu} \sigma-m_{\sigma}^{2} \sigma^{2}\right)-\frac{1}{4} \omega_{\mu \nu} \omega^{\mu \nu} \\
& +\frac{1}{2}\left(\partial_{\mu} \sigma^{*} \partial^{\mu} \sigma^{*}-m_{\sigma^{*}}^{2} \sigma^{* 2}\right) \\
& +\frac{1}{2} m_{\omega}^{2} \omega_{\mu} \omega^{\mu}-\frac{1}{4} \phi_{\mu \nu} \phi^{\mu \nu} \\
& +\frac{1}{2} m_{\phi}^{2} \phi_{\mu} \phi^{\mu}-\frac{1}{4} \rho_{\mu \nu} \rho^{\mu \nu} \\
& +\frac{1}{2} m_{\rho}^{2} \rho_{\mu} \rho^{\mu}
\end{aligned}
$$

dimana $\omega^{\mu \nu}, \phi^{\mu \nu}$, dan $\rho^{\mu \nu}$ adalah tensor medan yang berhubungan dengan medan meson $\omega$, $\phi$, dan $\rho$ yang dapat didefinisikan sebagai:

$$
\begin{gathered}
\omega^{\mu \nu}=\partial^{\mu} \omega^{v}-\partial^{v} \omega^{\mu}, \\
\phi^{\mu \nu}=\partial^{\mu} \phi^{v}-\partial^{v} \phi^{\mu}, \\
\rho^{\mu \nu}=\partial^{\mu} \rho^{v}-\partial^{v} \rho^{\mu} .
\end{gathered}
$$

Untuk Lagrangian interaksi linear antara baryon dan meson yaitu [4]:

$$
\begin{aligned}
& \mathcal{L}_{B M}^{\operatorname{lin}}=\sum_{B=N, \Lambda, \Sigma, \Xi} \bar{\psi}_{B}\left[g_{\sigma B} \sigma+g_{\sigma^{*} B} \sigma^{*}-\right. \\
& \left.\gamma_{\mu} g_{\omega B} \omega^{\mu}-\frac{1}{2} \gamma_{\mu} g_{\rho B} \tau_{B} \cdot \rho^{\mu}-g_{\phi B} \phi^{\mu}\right] \psi_{B}
\end{aligned}
$$

dimana $\tau_{B}$ adalah matriks isospin baryon. Berikutnya, lagrangian yang menjelaskan interaksidiri meson untuk $\sigma, \omega$ dan $\rho$ dapat ditulis sebagai [4]:

$$
\mathcal{L}^{\text {nonlin }}=-\frac{\kappa_{3} g_{\sigma N} m_{\sigma}^{2}}{6 m_{N}} \sigma^{3}-\frac{\kappa_{4} g_{\sigma N}^{2} m_{\sigma}^{2}}{24 m_{N}^{2}} \sigma^{4}
$$

$$
\begin{aligned}
& +\frac{\zeta_{0} g_{\omega N}^{2}}{24}\left(\omega_{\mu} \omega^{\mu}\right)^{2}+\frac{\eta_{1} g_{\sigma N} m_{\omega}^{2}}{2 m_{N}} \sigma \omega_{\mu} \omega^{\mu} \\
& +\frac{\eta_{2} g_{\sigma N}^{2} m_{\omega}^{2}}{4 m_{N}^{2}} \sigma^{2} \omega_{\mu} \omega^{\mu} \\
& +\frac{\eta_{\rho} g_{\sigma N} m_{\rho}^{2}}{2 m_{B}} \sigma \rho_{\mu} \cdot \rho^{\mu} \\
& +\frac{\eta_{1} g_{\sigma N}^{2} m_{\rho}^{2}}{4 m_{N}^{2}} \sigma^{2} \rho_{\mu} \cdot \rho^{\mu} \\
& +\frac{\eta_{2 \rho} g_{\omega N}^{2} m_{\rho}^{2}}{4 m_{N}^{2}} \omega_{\mu} \omega^{\mu} \rho_{\mu} \cdot \rho^{\mu}
\end{aligned}
$$

Dan kerapatan lagrangian lepton bebasnya yaitu [4]:

$$
\mathcal{L}_{l}^{\text {free }}=\sum_{l=e^{-}, \mu^{-}} \bar{\psi}_{l}\left[i \gamma^{\mu} \partial_{\mu}-M_{l}\right] \psi_{l}
$$

dimana $\psi_{l}$ adalah medan lepton $(e$ dan $\mu)$.

Untuk mendapatkan EOS, di sini kami menggunakan dua parameter set untuk setiap coupling constant. Parameter set BSP untuk coupling constant pada kerapatan lagrangian interaksi linear dan nonlinear untuk nucleon dan meson yang diambil dari referensi [19]. Sedangkan parameter set SU(6) symmetry untuk coupling constant pada kerapatan lagrangian interaksi linear antara hyperon dan strange meson yang diambil dari referensi [7].

Parameter set BSP digunakan karena parameter set ini memberikan deskripsi yang lebih baik dari properti global inti berhingga (finite nuclei) dan prediksinya terhadap properti materi nuklir sangat cocok dengan prediksi data dari ion berat [4]. Sedangkan parameter set SU(6) symmetry digunakan karena data-data eksperimen tentang hyperon terbatas karena kedalaman potensialnya [4].

Setelah EOS materi bintang neutron diperoleh, selanjutnya kita menurunkan persamaan TOV untuk menghasilkan properti bintang neutron. Persamaan TOV ini dapat diturunkan dari persamaan medan Einstein dengan asumsi simetri bola statik terpenuhi [20]. Untuk mengakomodasi asumsi tekanan anisotropik dalam inti bintang neutron, di awali dengan menggunakan tensor energi momentum sebagai $[4,8,9]$ :

$$
\begin{gathered}
T^{\mu \nu}=q g^{\mu \nu}+(\epsilon+q) u^{\mu} u^{\nu}+\sigma k^{\mu} k^{\nu} ; \\
\sigma=p-q
\end{gathered}
$$

dimana, $\sigma$ adalah faktor anisotropik, $p$ adalah tekanan radial, $q$ adalah tekanan tangensial, $g^{\mu \nu}$ adalah matriks ruang-waktu, $u^{\mu}$ dan $u^{v}$ adalah kecepatan vektor-4 fluida, $\epsilon$ adalah kerapatan energi total, $k^{\mu}$ dan $k^{v}$ adalah satuan kecepatan arah radial dengan $u^{\mu} k_{\mu}=0$.

Di sini kita menggunakan matriks standar ruang-waktu simetri bola, yaitu:

$$
d s^{2}=-e^{2 v} d t^{2}+e^{2 \lambda} d r^{2}+r^{2}\left(d \theta^{2}+\sin ^{2} \theta d \phi^{2}\right)
$$


Selanjutnya, substitusikan persamaan energi momentum di atas kedalam persamaan medan Einstein [21], maka diperoleh persamaan TOV untuk bintang neutron anisotropik yaitu [4]:

$$
\begin{aligned}
\frac{d P}{d r} & =-\frac{M \epsilon}{r} \frac{\left(1+\frac{p}{\epsilon}\right)\left(1+\frac{4 \pi r^{3}}{M}\right)}{(r-2 M)}-\frac{2 \sigma}{r} \\
\frac{d M_{G}}{d r} & =4 \pi r^{2} \epsilon
\end{aligned}
$$

Setelah persamaan TOV diperoleh, selanjutnya kita gunakan tiga model anisotropik yaitu model dari Doneva-Yazadjiev (DY), Herrera-Barreto (HB), dan Bowers-Liang (BL). Model DY mengasumsikan sigma berbentuk [9]:

$$
\sigma \equiv \Lambda\left(\frac{2 M}{r}\right) P
$$

Sedangkan untuk model HB sigmanya [8]:

$$
\sigma \equiv-\frac{r}{2} \frac{(1-h)}{h} P^{\prime}
$$

Dan untuk model BL sigmanya adalah [10]:

$$
\sigma \equiv-c\left[\frac{\epsilon-3 p}{1-\frac{2 M}{r}}\right](\epsilon+P) r^{2}
$$

Langkah terakhir, dengan metode numerik, kita bisa mendapatkan properti-properti bintang neutron dari persamaan TOV yang sudah dimodifikasi ke dalam tiga model di atas seperti, massa $\left(M_{G}\right)$, sigma $(\sigma)$, energy density $(\epsilon)$ dan jari-jarinya $(R)$.

\section{Hasil dan Pembahasan}

Dalam sub bab ini, kita akan membahas efek tekanan anisotropik pada bintang neutron yang diasumsikan terdapat hyperon di dalam intinya. Pada gambar 1 di samping, ditampilkan grafik perbandingan antara massa bintang neutron dengan jari-jarinya untuk beberapa model yang kami gunakan.

Dari gambar 1 tersebut dapat kita ketahui bahwa untuk model isotropik, dimana bintang neutron diasumsikan memiliki hyperon di dalam inti tanpa kontribusi dari tekanan anisotropik, massa maksimumnya hanya mencapai $M_{G}=1.74 M_{\odot}$ dengan jari-jari pada massa maksimum yaitu $R=$ $10,85 \mathrm{~km}$. Sedangkan jika diberikan tekanan anisotropik, massa maksimum bintang neutron untuk model DY dapat mencapai $M_{G}=2.08 M_{\odot}$ dengan jari-jari $R=11.29 \mathrm{~km}$. Massa maksimum untuk model HB mencapai $M_{G}=2.09 M_{\odot}$ dengan jari-jari $R=11.87 \mathrm{~km}$. Massa maksimum untuk model BL juga mencapai $M_{G}=2.08 M_{\odot}$ dengan jari-jari $R=11.89 \mathrm{~km}$. Sehingga dari data-data tersebut kita dapat menyimpulkan bahwa tekanan anisotropik dapat meningkatkan massa maksimum

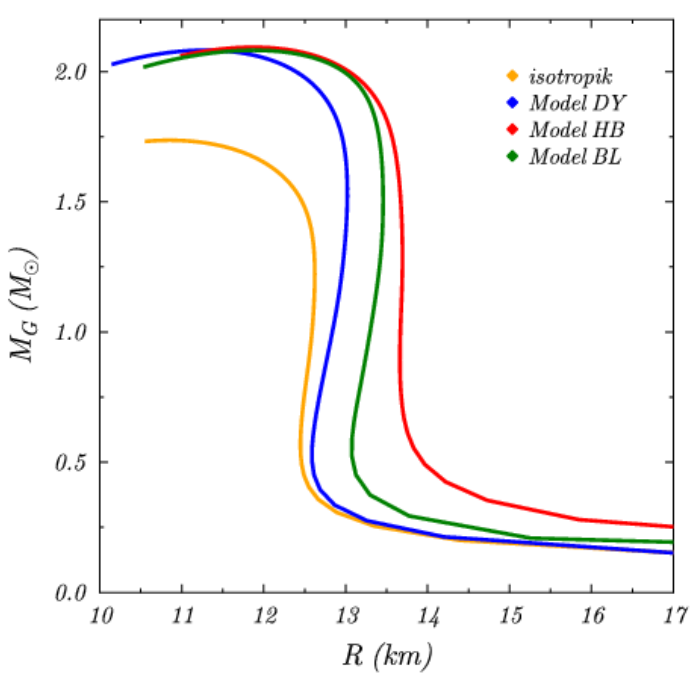

Gambar 1. Grafik perbandingan massa bintang neutron terhadap jari-jarinya, untuk model isotropik, Doneva-Yazadjiev (DY), Herrera-Barreto $(H B)$, dan Bowers-Liang (BL).

bintang neutron dengan partikel hyperon di dalam intinya secara konsisten. Hal ini sesuai dengan batas massa maksimum bintang neutron yang lebih rendah dari $2,1 M_{\odot}$ pada observasi massa dari PSR J1614-2230 dan PSR J0348+0432.

Untuk menunjukkan adanya tekanan anisotropik dalam inti bintang neutron, berikut ini ditampilkan grafik antara faktor anisotropik $(\sigma)$ terhadap jari-jari $(R)$ pada gambar 2. Untuk semua model anisotropik yang kami gunakan, baik model DY, HB dan BL, hasil faktor anisotropik $(\sigma)$ menunjukkan nilai yang negatif relatif terhadap jari-jarinya $(R)$.

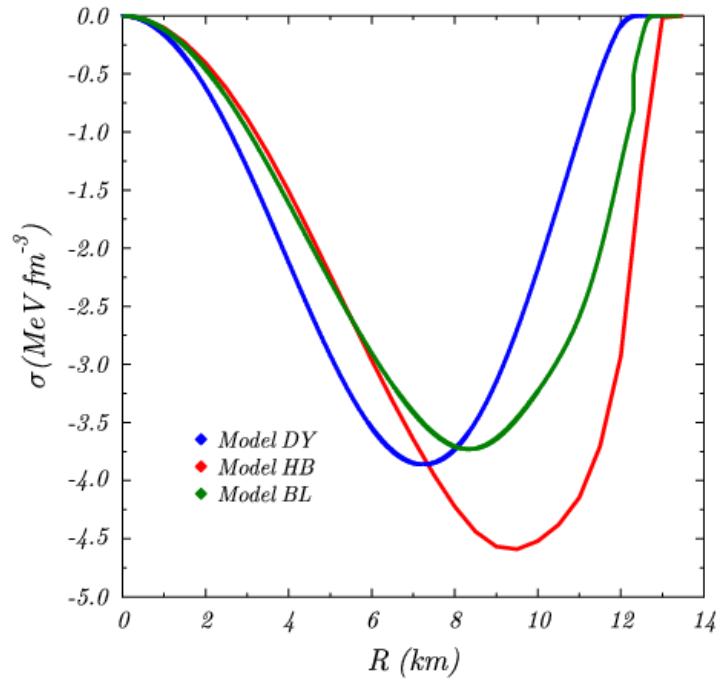

Gambar 2. Grafik antara faktor anisotropik ( $\sigma$ ) terhadap jari-jari $(R)$ untuk model DonevaYazadjiev (DY), Herrera-Barreto (HB), dan Bowers-Liang (BL). 
Pada gambar 2 di atas, untuk model DY, nilai maksimum $\sigma$ yang diperoleh sebesar $-3.86 \mathrm{MeVfm}^{-3}$, dengan jari-jari sebesar $7.22 \mathrm{~km}$. sedangkan untuk model $\mathrm{HB}$, nilai maksimum $\sigma$ yang diperoleh sebesar $-4.96 \mathrm{MeVfm}^{-3}$, dengan jari-jari sebesar $9.50 \mathrm{~km}$. Dan untuk model BL, nilai maksimum $\sigma$ yang diperoleh sebesar $-3.73 \mathrm{MeVfm}^{-3}$, dengan jarijari sebesar $8.34 \mathrm{~km}$.

Faktor anisotropik $(\sigma)$ merupakan selisih dari tekanan radial $(p)$ dengan tekanan tangensial $(q)$. Jika selisih nilai yang didapat dari kedua tekanan tersebut adalah nol, artinya tekanan yang bekerja pada bintang neutron tersebut adalah isotropik. Hal ini karena besar dari tekanan radial sama dengan tekanan tangensialnya. Namun jika faktor anisotropiknya $(\sigma)$ bernilai negatif, dapat kita simpulkan bahwa tekanan yang bekerja dalam bintang neutron adalah anisotropik. Hal ini menunjukkan bahwa tekanan anisotropik dalam bintang neutron sangat sensitif terhadap jari-jarinya.

Sebagai konsekuensi dari bekerjanya tekanan anisotropik pada bintang neutron ber-hyperon, berikut ini kami tampilkan grafik antara energy density $(\epsilon)$ di pusat massa bintang neutron terhadap jari-jarinya $(R)$ pada gambar 3 di bawah ini.

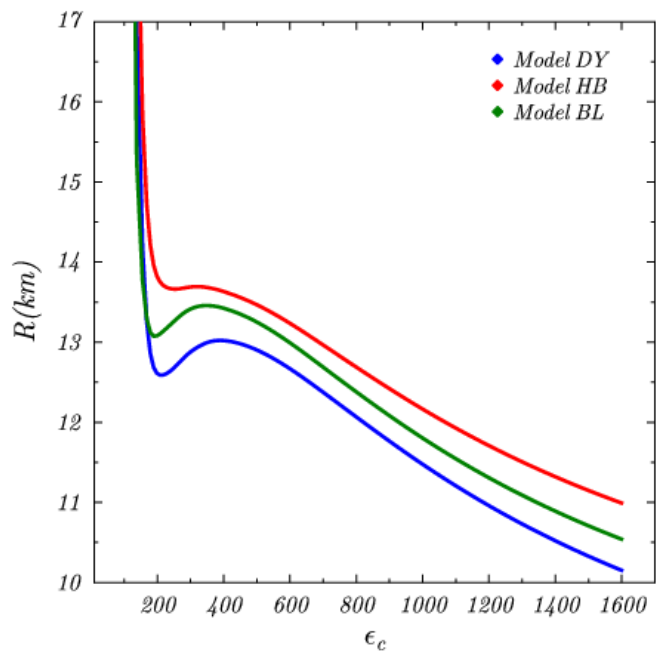

Gambar 3. Grafik antara jari-jari (R) terhadap energy density $(\epsilon)$ di pusat massa bintang neutron ber-hyperon dengan tekanan anisotropik.

Pada gambar 3 tampak bahwa perubahan besar jari-jari $(R)$ mempengaruhi energy density $(\epsilon)$ di pusat massa materi bintang neutron. Nilai energy density $(\epsilon)$ minimum untuk model DY, $\epsilon \sim 200$ dimiliki oleh bintang neutron dengan jari-jari sebesar $12.59 \mathrm{~km}$. Sedangkan untuk model HB, $\epsilon \sim 200$ dimiliki oleh bintang neutron dengan jarijari $13.82 \mathrm{~km}$. Dan untuk model BL, $\epsilon \sim 200$ dimiliki oleh bintang neutron dengan jari-jari $13.10 \mathrm{~km}$. Sehingga dari gambar 3 tersebut dapat kita simpulkan bahwa, nilai energy density di pusat massa semakin kecil saat jari-jari bintang neutron semakin besar. Selanjutnya, nilai energy density $(\epsilon)$ mencapai maksimum untuk model DY, $\epsilon \sim 1600$ dimiliki oleh bintang neutron dengan jari-jari hanya $10.14 \mathrm{~km}$. Sedangkan untuk model HB, $\epsilon \sim 1600$ dimiliki oleh bintang neutron dengan jari-jari yang tidak jauh berbeda, yaitu $10.98 \mathrm{~km}$. Dan untuk model BL, $\epsilon \sim 1600$ dimiliki oleh bintang neutron dengan jari-jari yang serupa, yaitu $10.54 \mathrm{~km}$. Sehingga dapat kita simpulkan bahwa semakin kecil jari-jari bintang neutron, energy density di pusat massa bintang semakin besar.

\section{Simpulan}

Dari semua data pada sub bab hasil dan pembahasan di atas, menunjukkan kepada kita bahwa untuk ketiga model (model DY, HB, dan BL) properti-properti seperti massa $\left(M_{G}\right)$, faktor anisotropik $(\sigma)$, energy density $(\epsilon)$, dan jari-jari $(R)$ bintang neutron dengan keberadaan hyperon di dalamnya memberikan hasil yang sangat meyakinkan. Hal ini tidak lain adalah karena peran tekanan anisotropik yang seakan-akan memberikan gaya repulsif di dalam inti bintang, sehingga mampu menaikkan massa bintang neutron berhyperon secara konsisten, sesuai dengan observasi massa dari PSR J1614-2230 dan PSR J0348+0432.

\section{Ucapan Terimakasih}

Terima kasih saya tujukan kepada Saipudin, M.Si selaku teman diskusi dalam melakukan komputasi program, sehingga waktu pelaksanaan penelitian menjadi lebih cepat.

\section{Daftar Acuan}

Jurnal

[1] P. B. Demorest, T. Pennucci, S. M. Ransom, M. S. E. Roberts, and J. W. T. Hessels, Nature 467, 1081 (2010)

[2] J. Antoniadis, P. C. C. Freire, N. Wex, T. M. Tauris, R. S. Lynch, M. H. van Kerkwijk, M. Kramer, C. Bassa, V. S. Dhillon, T. Driebe, J. W. T. Hessels, V. M. Kaspi, V. I. Kondratiev, N. Langer, T. R. Marsh, M. A. McLaughlin, T. T. Pennucci, S. M. Ransom, I. H. Stairs, J. van Leeuwen, J. P. W. Verbiest, and D. G. Whelan, Science (80-. ). 340, 1 (2013).

[3] B. Kiziltan, A. Kottas, M. De Yoreo, and S. E. Thorsett, Astrophys. J. 778, 66 (2013).

[4] A. Sulaksono, Int. J. Mod. Phys. E 24, 1550007 (2015).

[5] J. L. Zdunik and P. Haensel, Astron. Astrophys. 61, 1 (2013).

[6] B. D. Lackey, M. Nayyar, and B. J. Owen, Phys. Rev. D 73, 024021 (2006). 
[7] J. Schaffner-Bielich and A. Gal, Phys. Rev. C 62, 034311 (2000).

[8] L. Herrera and W. Barreto, Phys. Rev. D 88, 084022 (2013).

[9] D. D. Doneva and S. S. Yazadjiev, Phys. Rev. D 85, 124023 (2012).

[10] R. L. Bowers and E. P. T. Liang, Astrophys. J. 188, 657 (1974).

[11] D. Horvat, S. Ilijić, and A. Marunović, Class. Quantum Gravity 28, 025009 (2011).

[12] T. Harko and F. S. N. Lobo, Phys. Rev. D 83, 124051 (2011).

[13] P. H. Nguyen and J. F. Pedraza, Phys. Rev. D 88, 064020 (2013).

[14] J. P. Mimoso, M. Le Delliou, and F. C. Mena, Phys. Rev. D 88, 043501 (2013).

[15] I. Bednarek, P. Haensel, J. L. Zdunik, M. Bejger, and R. Ma, Astron. Astrophys. 157, 1 (2012).

[16] A. Sulaksono and B. K. Agrawal, Nucl. Phys. A 895, 44 (2012).

[17] W. Jiang, B. Li, and L. Chen, Astrophys. J. 756, 56 (2012).

[18] S. Weissenborn, D. Chatterjee, and J. Schaffner-Bielich, Phys. Rev. C 85, 065802 (2012).

[19] B. K. Agrawal, A. Sulaksono, and P.-G. Reinhard, Nucl. Phys. A 882, 1 (2012).

[20] N. K. Glendenning, Compact Stars: Nuclear Physics, Particle Physics and General Relativity, Second edi (Springer, New York, 2000).

[21] J. P. W. Diener, Relativistic Mean-Field Theory Applied to the Study of Neutron Star Properties, 2008. 
